\title{
Perceived Psychological Resilience among the Survivors of a Tragedy in Kenya: A Theoretical Approach
}

\author{
Lenah $\mathrm{Sambu}^{1 *}$
}

\section{ABSTRACT}

This paper sought to examine the perception of survivors of tragedy in Kenya on Psychological Resilience. The study adopted a mixed design approach. The target population for this study was 50. It comprised all individuals who were victims of the fire tragedy at Kiambaa village. Questionnaires and unstructured interview schedule were the main tools of data collection. The 25 item Connor-Davidson Resilience Scale 25 (CD-RISC-25) (used with permission) Connor and Davidson (2003) was used to measure the resilience levels of the respondents. Means and Standard deviations were computed to quantify the amount of variation or dispersion of resilience among the respondents. Responses from research tools were cleaned, coded and entered into Statistical Package for Social Sciences (SPSS) for analysis. Pearson product moment correlation analysis, Chi square correlation analysis and Spearman rank correlation analysis were computed to establish the relationships between study variables. Findings were presented in form of tables, cumulative frequency counts, graphs and charts.

Keywords: Psychology, Resilience, Trauma, Tragedy, Violence

In psychology, the focus of resilience paradigm is on the individual. Fletcher and Sarkar (2013) emphasized that "it is the study of psychological resilience that seeks to understand why some individuals are able to withstand - or even thrive on - the pressure they experience in their lives" (p. 12).

When people experience tragic events such as violence they get traumatized. Most of them are not able to carry out their normal routine tasks (Robert, 2005). They experience a wide range of reactions, positive and negative. Their strengths and abilities increase and decrease making it possible to gain control of their lives differently.

\footnotetext{
${ }^{1} \mathrm{PhD}$, Department of Sociology and Psychology, Moi University, Eldoret, Kenya

*Responding Author

(c) 2016 I L Sambu; licensee IJIP. This is an Open Access Research distributed under the terms of the Creative Commons Attribution License (http://creativecommons.org/licenses/by/2.0), which permits unrestricted use, distribution, and reproduction in any Medium, provided the original work is properly cited.
} 
After violence, people will most likely face challenges and experience significant psychological, social, vocational and emotional difficulties. Despite these challenges, there are individuals who are able to adopt and bounce back with minimal disruption to their lives. Others are eventually able to recover close to their pre-trauma level of functioning, though this is rare (Curtis \& Nelson, 2003). Although their present functioning may not be exactly as it was in pre-trauma, a new baseline can be established where the survivors learn new skills and ways to cope with the situations.

Resilience is a crucial area for psychologists to assess individuals and strengthen them particularly those who have experienced various life threatening traumatic events. Resilience is relevant to traumatized people's adjustments to setbacks that arise from the tragedy. According to the available literature, little research has addressed factors that contribute to resilience after trauma and the psychological and individual experiences.

Several theories have attempted to elucidate resiliency factors, their inter-relationships, as well as their underlying mechanisms, processes, and outcomes. These theories have emerged from personality, cognitive and biological orientations. However, the theoretical concepts of Richardson's “met theory of resilience and resiliency” and Joseph and Linley "organism valuing theory” guided this study on investigation of psychosocial resilience perception by survivors.

\section{Richardson's Meta-theory of Resilience and Resiliency}

Richardson (2002) conceptualized that resilience is a force within everyone that drives them to seek self-actualization, altruism, wisdom and be in harmony with a spiritual source of strength. He identified three different waves of resiliency enquiry; characteristics of people who effectively cope with and grow through disruption, the process in which such people acquire these characteristics and the recognition of innate resilience and the capacity to grow and develop. According to the theory, resilient reintegration develops by the strengthening of the resilient qualities.

According to this theory an individual begins at a state of physical, mental and spiritual homeostasis (biopsychospiritual homeostasis - figure 1), then disruption occurs, in this case -the fire tragedy. After the disruption the individuals reintegrated to homeostasis in one of the four ways: resilient reintegration, re-integration back to homeostasis, re-integration with loss and dysfunctional re-integration. This paper specifically focuses on the resilient reintegration and the protective factors (age, gender, personality traits, spirituality and social support) that contributed to it. The essence of re-integrating to homeostasis in some cases may not be an option in situations such as permanent physical loss, mobility loss or death of a loved one. Recovering with loss means that people give up some motivation, hope or drive because they are prompted to by the demands of life. Dysfunctional reintegration occurs when people resort to use of destructive substances (Figure 1). Resilience reintegration may also be postponed and people may resort to negative coping mechanism such anger, distrust and bitterness. Years later such 
individual's coping pattern may be disrupted and they may reintegrate to healthier coping skills, this may occur through social support and intensive spiritual support. Richardson further asserts that there are protective factors that assist the individual to reach the stage of resilient reintegration and which comprise an adaptive state of mind, body and spirit, which according to Richardson (2002) is the attainment of biopsychospiritual homeostasis and this state can be achieved regardless of the circumstances of the individual.

Figure 1: The Metatheory of Resilience and Resiliency

Source: Richardson (2002)

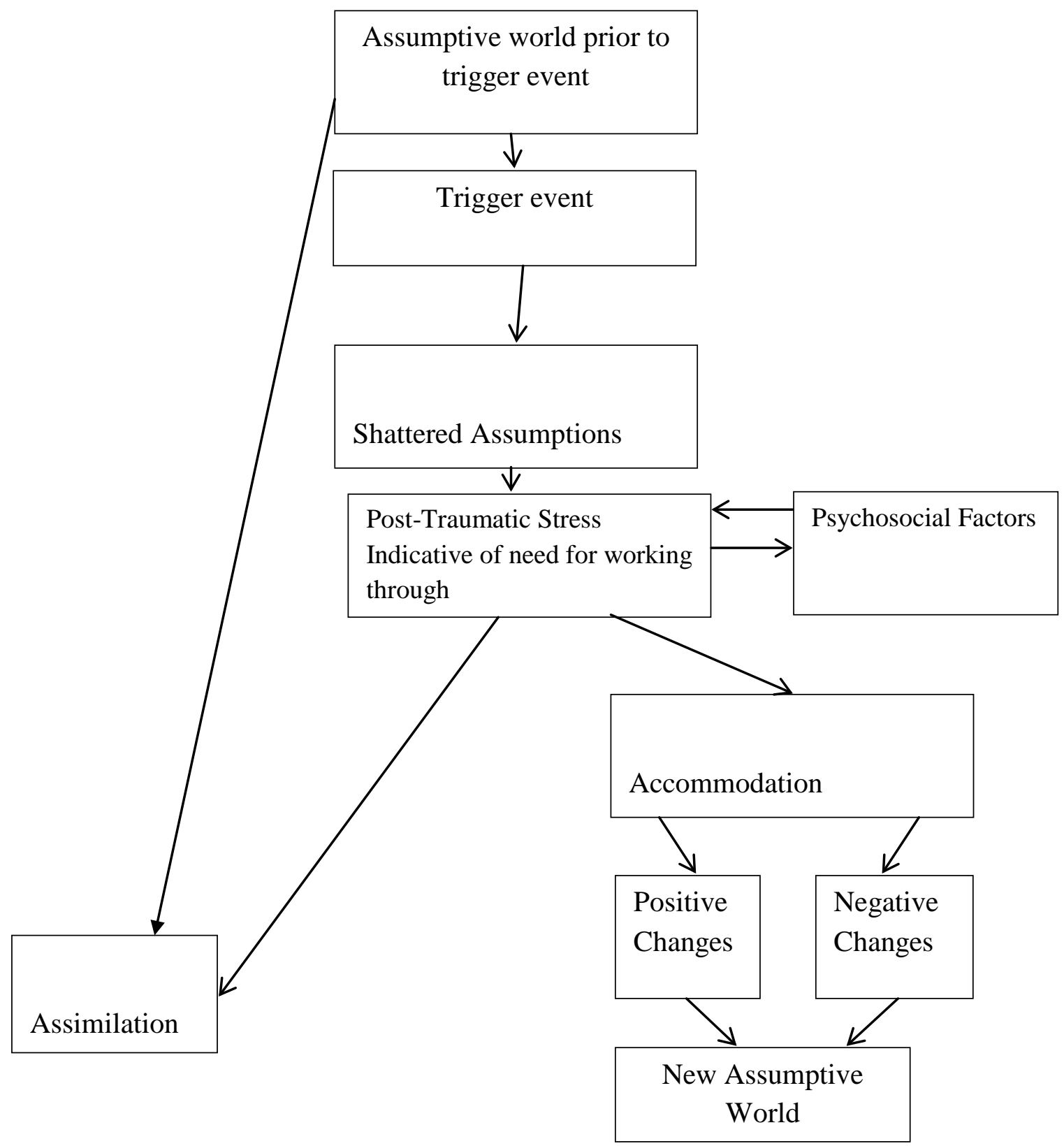




\section{Joseph and Linley Organismic Valuing Theory}

This study is informed by Joseph and Linley (2005) in "organismic valuing” theory, which stems from Carl Rogers Person Centered approach, who posit that people are intrinsically motivated to rebuild their lives in a direction consistent with the new trauma- related information. According to the theory, new trauma-related information can be processed either by being assimilated within the existing models of the world or existing models of the world must accommodate the new trauma-related information. The accommodation may require individuals to change their world views. Accommodation can either be negative which may include hopelessness and helplessness, or positive direction dependent on the meaning attributed to the traumatic event (Payne, Joseph, \& Tudway, 2007). The theory gives three possible outcomes; the experiences that can be assimilated to the pre-trauma baseline, the experiences that can be accommodated in a negative direction (psychopathology) and experiences that can be accommodated in a positive direction (growth). The theory shows how people's valuing process can lead to actualization of positive changes and psychological well-being through the positive accommodation of the new trauma related information which is provided by the social environment (Figure 2). This leads to greater psychological well-being, although it does not necessarily lead to greater subjective wellbeing. The theory holds that this occurs when the social environment is able to meet the individual's psychological needs for autonomy, competence, and relatedness, and the organisms valuing process is then promoted.

Organismic valuing theory holds that it is human nature to strive to integrate new experiences and to reorganize the self-structure accordingly, to modify existing models of the world to positively accommodate the new trauma-related information. Adverse events show that people are fragile, that the future is uncertain, and when this happens to the self-structure it may lead to intrusive and avoidant states which are characteristic of post-traumatic stress disorder (PTSD). The person goes through a series of oscillating phases of intrusion and avoidance as the new trauma-related information is processed, this continues until a baseline is reached.

\section{Figure 2: Organismic Valuing Theory of Resilience following Adversity} Source: Joseph and Linley (2005)

The theory is also consistent with the notion that accommodation rather than assimilation is necessary for growth. It specifies that accommodation may occur either positively or negatively. When a baseline is reached and intrusive and avoidant states are no longer present, the cognitive assimilation of the traumatic memory or a revision of existing schemas to accommodate new information has been achieved by the person. However, this may be challenging and may require a supportive social environmental context that facilitates satisfaction of the basic psychological needs for autonomy, competence and relatedness. These needs act as factors of resiliency that direct the person towards positive accommodation of the traumatic event. 
The theory also specifies the importance of comprehensibility which is significant in deriving meaning as people struggle with the traumatic event and when this is achieved assimilation or accommodation of the information may occur. In this theory the positive benefit is found in psychological growth which is facilitated by factors such as satisfaction of basic psychological needs which include affiliation, autonomy, competency and a supportive social environment.

Based on this theory, this study attempted to find out the perceived psychosocial resilience among the affected people of Kiambaa village that may have resulted to some individuals experiencing assimilation and others accommodation after the disruption or trauma from the fire tragedy. According to Joseph and Linley (2005) assimilation is simply returning to assumptive world before trauma and this was also conceptualized by Richardson (2002) as re-integration to homeostasis. Accommodation happens when individuals strive to integrate new experience which according to the theory it may result to positive or negative changes that will lead to the individuals acquiring new assumptions of the world (Calhoun, Cann, \&Tedeschi, 2010).

Amering and Schmolke (2009) asserted that resilience was used to imply the power to resist, mental elasticity and regaining the former mental stability following a stressful period or event in clinical psychology and psychotherapy. Kelley and Pransky (2013) equated psychological resilience with inner health and asserted that "innate resilience...is the essence of a balanced, healthy state of mind evidenced by the logic of fundamental principles that appear to account for all human experience” (p. 2).

\section{METHODOLOGY}

The study is philosophically underpinned in the descriptive-interpretive qualitative research applied within a mixed method design. This study employed mixed methods research design which is a procedure for collecting, 128 analyzing and "mixing” both quantitative and qualitative research methods in a single study in order to understand a research problem better (Creswell, 2012).

To attain a complete understanding of psychological resilience in fire survivors and to ensure comprehensiveness of study results, a mix of qualitative and quantitative research methods were employed. The aim for choosing sequential exploratory design was the lack of a verified framework for explaining psychological resilience. As in every mixed-methods design, the critical components of the sequential exploratory design is (1) the level of interaction between the qualitative and quantitative strands, (2) the relative priority of the strands, (3) the timing of the strands, and (4) the procedures for mixing the strands (Creswell \& Plano Clark, 2011).

A semi-structured interview protocol was used to collect in-depth information from survivors of the Kiambaa fire tragedy. According to Patton (2002), semi-structured type of interviewing allows natural and spontaneous interaction on the topic. 
The semi-structured interview schedule consisted of questions focusing on the factors perceived by the individuals exposed to the fire tragedy as associated with psychological resilience. The questions followed a logical order, from more general questions to more specific ones. The interview began with a general question regarding psychological resilience. Interviewees were then asked how resilient they perceived themselves and why. Data was organized and presented thematically.

\section{FINDINGS AND DISCUSSION}

The aim of the study was to investigate perceived psychological resilience in the survivors of the 2008 fire tragedy in Kiambaa Village, Eldoret District, UasinGishu County, Kenya. Personality, Spirituality and social support were the basis to which the results on the perception of psychological resilience were reported. The findings thus show five sampled participants of different age groups that were interviewed.

The purpose was to provide an extensive description of the sample and add more in-depth and richer insight (Yin, 2003). These individuals were perceived to be the most traumatized because they were inside the burning church and incurred physical injuries and lost the loved ones in the fire tragedy (researcher, 2014).

Participant 1, age 30 years was a married female who was self employed and a housewife. She had achieved up to primary school level of education and her loss in this case was child and property.

\section{Personality characteristics}

The participant indicated that she feels confident, is emotionally stable and rarely gets upset. After the traumatizing experience of the fire tragedy following the post election violence, she decided to move on and overcome the pain, bitterness and anger. She described herself as organized, a good planner and emotionally stable. Her general perspective about life is positive and this she believes helped her cope with the adversities she faced her after the fire tragedy. She explained she was generally talkative, and enjoyed the company of others.

\section{Spirituality}

The participant and her family were active members in church, she indicated that she experienced spiritual growth after the adversity and this helped her deal with the trauma. She believed that her spiritual faith gave her hope and motivation which enabled her to stay well during the traumatizing period. She also believed that God's power gave her strength and meaning to move on with life despite the traumatizing issues she faced. Through spirituality, she learnt to forgive her aggressors; this helped her to experience religious purification and peace. She learnt to trust God for protection/security and never doubted his supernatural power. She also indicated that she offered spiritual care to others who were more traumatized which gave her more meaning to life. The participant indicated that she prayed persistently during the time of 
adversity, and she believed God answered her prayers because she experienced peace and emotional calmness.

\section{Social support}

The participant explained that she received support from her family members, particularly her husband and parents. She also received substantial support from counselors, social workers, religious groups and volunteers. The participant also indicated that she offered help to others who were more traumatized than her. At the time of the interview, she was actively involved in church activities which include supporting and encouraging each other. Generally, the participant believed she had adapted and had learnt to cope with the post trauma situations. She indicated she had a strong faith and purposeful life and was optimistic about the future.

In the above case, the participant has a positive perception to psychological resilience as she believes that striving through; forgiveness; prayer and family support has helped her thrive. She is very optimistic.

Participant 2, a male respondent who was aged 28 years married and self-employed business man said he had attended school to a primary level. He had lost his parents and property.

\section{Personality characteristics}

This business man believed he possesses capabilities to organize and execute courses of action required to manage adversity. He described himself as resourceful and of high self-esteem. He believed these personal characteristics helped him cope with the trauma he faced after the adversity. He also indicated that he had high interpersonal abilities such as social skills, problem solving and impulse control. He had secure attachments with his family and friends and this helped him cope with the trauma after the adversity. He also indicated that he was emotionally stable and felt accomplished.

\section{Spirituality}

Participant 2 indicated that he lived a spiritual life, he attended church and appreciated that: "God is first in life". He believed he was close to God and that God provided the necessary support he needed at the time of the adversity. He trusted for protection and security after the adversity. He believed he received the miracle and things turned around and he was able to bounce back after the traumatic episode. His source of strength according to him was his ability to forgive and forget; this he said was instrumental in the healing process. He believed his spirituality helped him deal with; anger, bitterness, guilt, aggression, anxiety, panic attacks and fears that he experienced after the fire tragedy.

\section{Social support}

The participant received social support from friends, family, counselors, volunteers, spiritual leaders and other agencies. This support he says helped him to learn to appreciate others and got 
encouraged as he interacted with others and also as they shared the experiences. He believed his family played a major role in enhancing his recovery after the trauma. He indicated that his father and uncle were his role models and his pillar. This participant believed that the attachment he had with his family provided him with love and a sense of belonging. His community members were also instrumental in offering social support although he valued the support from his family members more.

The responses above indicate that the respondent was confident that his personality, spiritual life and social support from family have helped him push though the fire tragedy ordeal. He believed he was close to God and that God provided the necessary support he needed at the time of the adversity, protecting and securing him against all odds.

Participant 3, was a female widow aged 40 years that was a self-employed farmer having gone up to primary level of education. She had lost her husband and property in the tragedy.

\section{Personality characteristics}

Had high feelings of anxiety, anger, guilt, bitterness and was often in depressed moods. She was fond of blaming others for negative issues in her life and tended to be sensitive and shy. Problems overwhelmed her and during the time of the fire tragedy, she developed serious depressive episodes. She was in a state of denial for a long time and said she rarely shared her feelings with others.

\section{Spirituality}

Participant 3 indicated that she was an active member of her local church and participated regularly in church activities. She participated in the church support group and fellowships and these activities boosted her morale and spirituality. Her spiritual life was a strong part of her that gave her a new phase in her life after the trauma. She indicated that her spirituality had given her a new meaning of life. She was at peace because through her spirituality, she learnt about forgiveness and this helped her deal with the feelings of anger, bitterness, anxiety and depressed moods. Spirituality gave her a new meaning of life after the adversity.

\section{Social support}

The participant indicated that she had adapted well to the trauma and loss she encountered after the fire tragedy. She received social support from family, friends, relatives, counselors, social workers, government health workers and other community based workers. The participant believed the social support from family and others provided her with understanding, companionship, and sense of belonging and positive self-regard. This participant also indicated that she was engaged in offering support activities to others because she had understood the importance of social support, and the positive outcomes it contributes to stressed individuals. 
Filled with anger and bitterness, this responded was adversely depressed, affected by the trauma. She however felt at peace through her spiritual wellbeing, and this helped her lot with the social support she received from family. This is an indication that even though the psychological resilience was minimal, one is always able to strive though with support.

Participant 4 was a female widow, also aged 65 years, a farmer who had no formal education; she was reported to have lost her relative and property.

\section{Personality characteristics}

The responded described herself as a woman of high self-esteem and could easily adapt to change. This, she believed, helped her cope with the adversity. Her approach to life was action oriented and she set her personal goals on how to survive after the adversity and this helped her deal with the trauma and subsequent losses. She believed she would adjust because she had experienced similar episodes before and had managed to move on. She had matured after going through the experience of losing a loved one. She believed that the tough episodes she had experienced gave her more courage to develop coping strategies. She described herself as a patient and loving person who forgave willingly the neighbors who violently harmed them.

\section{Spirituality}

The participant indicated that she was a staunch member of her local Christian church and she loved singing in the church choir. She cherished being involved in the activities of the church, such as helping others through fellowship meetings and home visits. Her spirituality was a great resource and she had faith she could overcome any stress/adversity. She spoke passionately of her religious beliefs and believed God was in control of every situation. During the time of the tragedy she totally surrendered all her tribulations to God; this gave her peace and motivation to move on. She did not take pride of any personal achievements. According to her, "all the glory and honour goes to God, without Him I would not have made it".

\section{Social support}

Participant 5 received substantial social support from family, relatives, friends, health professionals, community members and other agencies. She noted that the social support was instrumental to her during the healing process. After she recovered from the trauma, she engaged in providing social support to others who were experiencing regression and were taking too long to recover. The participant believed that through social support she developed secure attachment with others particularly members of her family and members of the community.

Self esteem was an enabling factor to get through the fire tragedy adversity. Religious believe and social support was also factors that helped. 
Participant 5 on the other hand, was an elderly of age 75years male who was a married poultry farmer that in the tragedy had lost his daughter, grandchildren and property. He had no formal education.

\section{Personality characteristics}

Participant 5 described himself as patient, tolerant and optimistic about the future. He had encountered adversities in the past and he was not overwhelmed. He believed he had a powerful internal locus control and had the ability to adopt to change. At the age of 75, he was able to set personal or collective goals and organize issues well. He indicated that he was committed to live a meaningful and resourceful life. He admitted that he was severely affected by the tragedy but he chose to be strong and courageous and moved on despite the trauma her was experiencing.

\section{Spirituality}

The participant believed his spirituality assisted him cope with the trauma. It gave him hope and confidence to move on. He said "it is comforting to know you are not alone, but there is a higher power watching over you". He believed God bailed him out of the pain and anguish he was experiencing after the trauma. He prayed persistently and God answered his prayers and for him, God was his great source of strength.

\section{Social support}

The participant received social support from family, relatives, friends, counselors, social workers, members of the community, and religious leaders. The participant received emotional support, instrumental support and informational support. He indicated that the social support helped him to overcome the stresses he faced after the adversity. He appreciated all types of support he received.

\section{CONCLUSION}

In this paper, psychological resilience has been defined as the ability to bounce back from and withstand adversities and threatening situations by maintaining healthy levels of psychological functioning. From the findings of the study, social support, spirituality and personal characteristics are seen as among those factors that helped individual survivors thrive through traumatic, adverse events. It may be assumed that these factors enabled them to assimilate or accommodate positive/negative changes and formed new assumptions of the world (Joseph \& Linley, 2005). The factors may also have assisted the individuals to work through the posttraumatic stress they experienced and this could have resulted to their resilient reintegration (Richardson, 2002).

\section{RECOMMENDATIONS}

The researcher also recommends that there is need to extend the present study by including other potentially important variables such as a wider range of psychosocial resources or health-related 
variables. Understanding the influence and importance of these variables may help to clarify the role of resilience in post-disaster adaptation.

In addition, the researcher recommends that there is need to further extend the study to investigate the relationship between psychological resilience and another positive outcome, such as posttraumatic growth (PTG).

\section{REFERENCES}

Amering, M., \& Schmolke, M. (2009). Recovery in mental health reshaping scientific and clinical responsibilities. London: Wiley-Blackwelll.

Calhoun, L. G., Cann, A., \&Tedeschi, R. G. (2010). The Posttraumatic Growth Model: Sociocultural considerations. In T. Weiss \& R. Berger (Eds.), Posttraumatic growth and culturally competent practice (pp. 1-14). Hoboken, NJ: Wiley \& Sons. Journal of Social Issues, 38(2), 193-208.

Connor, K., \& Davidson, J. (2003). Development of a new resilience scale: The ConnorDavidson Resilience Scale (CD-RISC). Depression and Anxiety, 18, 7682.http://dx.doi.org/10.1093/bjsw/bcm047.

Creswell, J. W., Plano Clark, V. L., Gutmann, M., \& Hanson, W. (2003). Advanced mixed methods research designs. In A. Tashakkori \& C. Teddlie (Eds.), Handbook of mixed methods in social and behavioral research (pp. 209-240). Thousand Oaks, CA: Sage Publications.

Creswell, J. W., \& Zhang, W. (2009). The application of mixed methods designs to trauma research. Journal of Traumatic Stress, 22(6), 612-621.

Cutis, W. J., \& Nelson, C. A. (2003). Towards building a better brain: Neuro-behavioral outcomes Mechanisms and processes of environment enrichment: In S. Luthar (Ed.) Resilience and vulnerability Adaptation in the context of Childhood Adversities (pp. 463488) New York: Cambridge University Press.

Fletcher, D., \& Sarkar, M. (2013). Psychological resilience: a review and critique of definitions, concepts, and theory. European Psychologist, 18(1), 12-23.

Joseph, S., \& Linley, P. A. (2005). Positive adjustment to threatening events: An organism valuing theory of growth through adversity. Review of General Psychology, 9,262-280.

Kelley, T. M., \&Pransky, J. (2013). Principles for realizing resilience: a new view of trauma and inner resilience. Journal of Traumatic Stress Disorders \& Treatment, 2(1), 1-9. doi:10.4172/2324-8947.1000102.

Patton, M. Q. (2002). Qualitative evaluation and research methods (3rd ed.). Newbury Park, CA: Sage Publications, Inc.

Payne, A.J., Joseph, S., \&Tudway, J. (2007). Assimilation and accommodation processes following traumatic experiences. Journal of Loss and Trauma, 12, 73-89. doi:10.1080/15325020600788206.

Richardson, G. E. (2002). The metatheory of resilience and resiliency. Journal of Clinical Psychology, 58, 307-321. 
Perceived Psychological Resilience among the Survivors of a Tragedy in Kenya: A Theoretical Approach

Robert, C. (2005). The Trauma Spectrum Hidden Wounds and Human Resiliency. New York: Norton.

Yin, R.K. (2003). Case Study Research: Design and Methods (3 ${ }^{\text {rd }}$ Ed.). London: Sage Publications.

\section{Website:}

https://en.wikipedia.org 